\title{
A Stercoral Perforation of the Rectum
}

\author{
Seung-Jin Kwag, Sang-Kyung Choi, Ji-Ho Park, Eun-Jung Jung, Chi-Young Jung, Sang-Ho Jung, Young-Tae Ju \\ Department of Surgery, Gyeongsang National University Hospital, Postgraduate School of Medicine, Gyeongsang National University, Jinju, \\ Korea
}

A stercoral perforation of the rectum due to a fecaloma is a rare disease with a high mortality rate. Although multiple case reports of colonic perforations have been published, the data regarding rectal perforations are limited. This case report will highlight one such case of a stercoral rectal perforation that was successfully treated with a laparoscopic operation.

Keywords: Constipation; Fecal impaction; Perforation; Rectum

\section{INTRODUCTION}

A stercoral perforation of the rectum is a rare disease with poor prognosis [1]. The pathogenesis of the disease is not clear, but this condition seems to be correlated with chronic constipation [2]. Unfortunately, when undertreated, constipation can lead to lifethreatening complications, including stercoral perforations of the colon and rectum. This report concerns a patient with a stercoral perforation of the rectum who underwent a laparoscopic Hartmann's operation.

\section{CASE REPORT}

An 83-year-old female patient was admitted to Gyeongsang National University Hospital because of diffuse abdominal pain and rectal bleeding that had begun began 24 hours earlier She had a 10 -year history of chronic constipation. She had no underlying disease and no history of abdominal surgery. Clinical examination demonstrated a diffuse abdominal pain, mainly located in the lower abdominal area, but no rebound tenderness was found on palpation. She was hemodynamically stable. Laboratory examination showed that the white blood cell count was 12,250 cells $/ \mathrm{mm}^{3}$

Received: October 10, 2012 • Accepted: March 15, 2013

Correspondence to: Young-Tae Ju, M.D.

Department of Surgery, Gyeongsang National University Hospital,

Postgraduate School of Medicine, Gyeongsang National University,

79 Gangnam-ro, Jinju 660-702, Korea

Tel: +82-55-750-8096, Fax: +82-55-750-9244

E-mail:drjyt@yahoo.co.kr

(C) 2013 The Korean Society of Coloproctology

This is an open-access article distributed under the terms of the Creative Commons Attribution NonCommercial License (http://creativecommons.org/licenses/by-nc/3.0) which permits unrestricted noncommercial use, distribution, and reproduction in any medium, provided the original work is properly cited. (segment form, 91.7\%), the hemoglobin was $12.6 \mathrm{~g} / \mathrm{dL}$ and the Creactive protein was $4 \mathrm{mg} / \mathrm{L}$. Abdominal computed tomographic (CT) scan revealed free air in the upper rectum mesorectum and diffuse thickening of the rectum wall (Fig. 1). A transverse image shows fecal impaction and retroperitoneal air (Fig. 2). On the CT scan, fluid collection was found to be localized in the pelvic cavity. Emergency surgery was performed by using a laparoscopic procedure. One 11-mm camera port was inserted just above the umbilicus, and three additional working ports were placed in the abdominal quadrants. The size of the right lower quadrant port was $12-\mathrm{mm}$ whereas the remaining ports were $5-\mathrm{mm}$ in size. We found a perforation site in right side wall of the upper rectum and turbid ascites. Except for the pelvic cavity, other intra-abdominal cavities were clean. Stool throughout the rectum was removed using an endobag. Laparoscopic Hartmann's procedure was performed. The inferior mesenteric pedicle was divided at its origin. To minimize the contamination due to discharged stool, we used a linear stapler to transect the sigmoid colon at the level of the rectosigmoid junction. The rectum containing the perforated lesion was transected and extracted by using an endobag throughout the colostomy site. We identified the irregular perforation of the right wall of the rectum (Fig. 3) and a significant amount of firm stool in the specimen (Fig. 4). The patient recovered well without postoperative complications and was discharged on the 9th postoperative day.

\section{DISCUSSION}

Stercoral perforation is a rare surgical finding. The disease was first described by Berry in 1894 [3], and to date almost 150 cases of stercoral perforation of the colon have been reported in English literature [4]. Stercoral perforation is a life-threatening condition presenting with a high mortality rate. The etiology of stercoral 


\section{Coloproctology

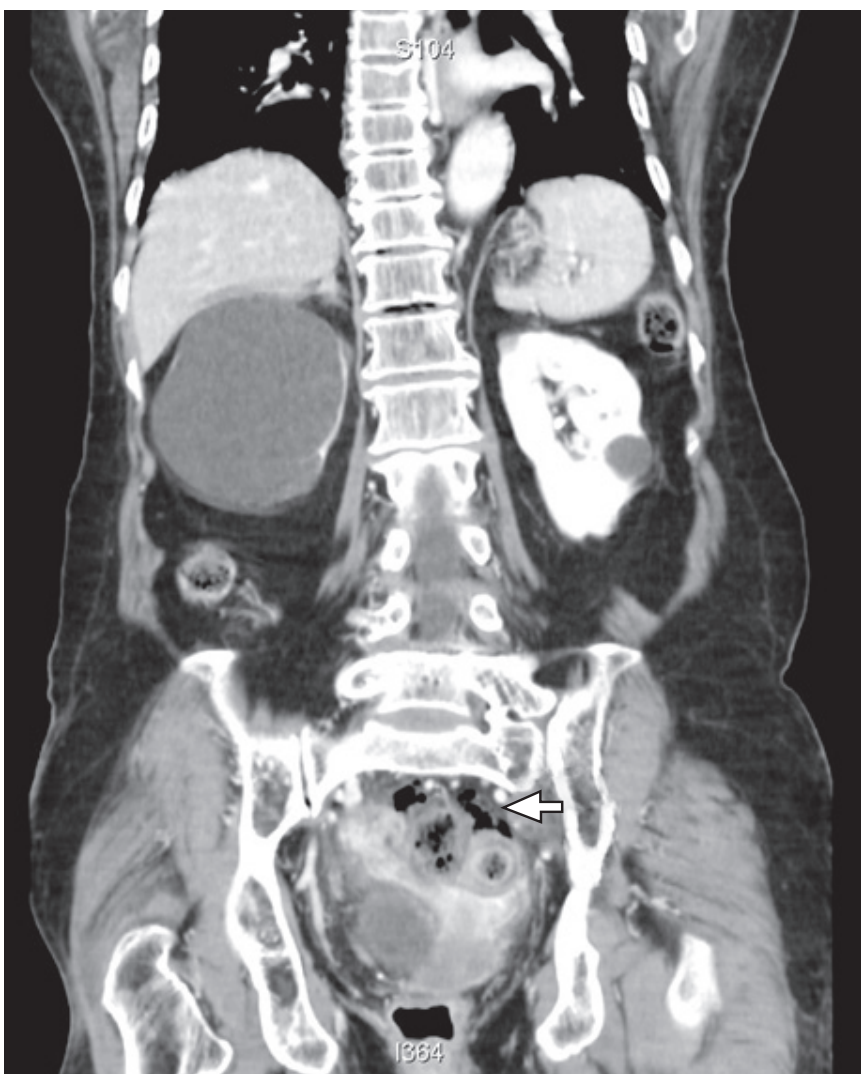

Fig. 1. Coronal image showing an extraluminal air bubble (arrow) and diffuse thickening of the rectum wall.

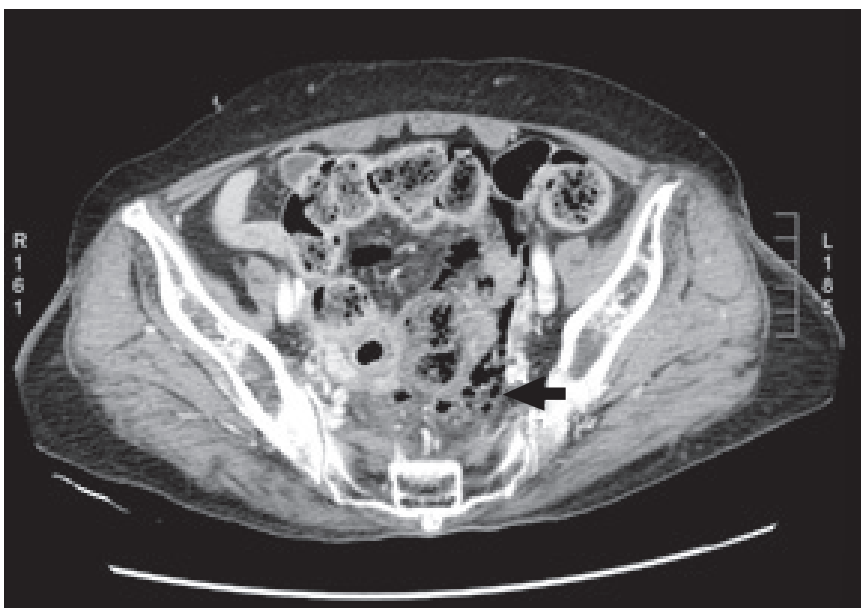

Fig. 2. Transverse image showing fecal impaction and retroperitoneal air (arrow).

perforation appears to be multifactorial. As with fecal impaction, most cases have been reported in elderly, psychiatric, bedridden, or narcotic-dependent patients with a history of constipation [5]. The pathogenesis of stercoral perforation is not clear, but chronic constipation and fecaloma seem to favor feculent ulcer alterations.

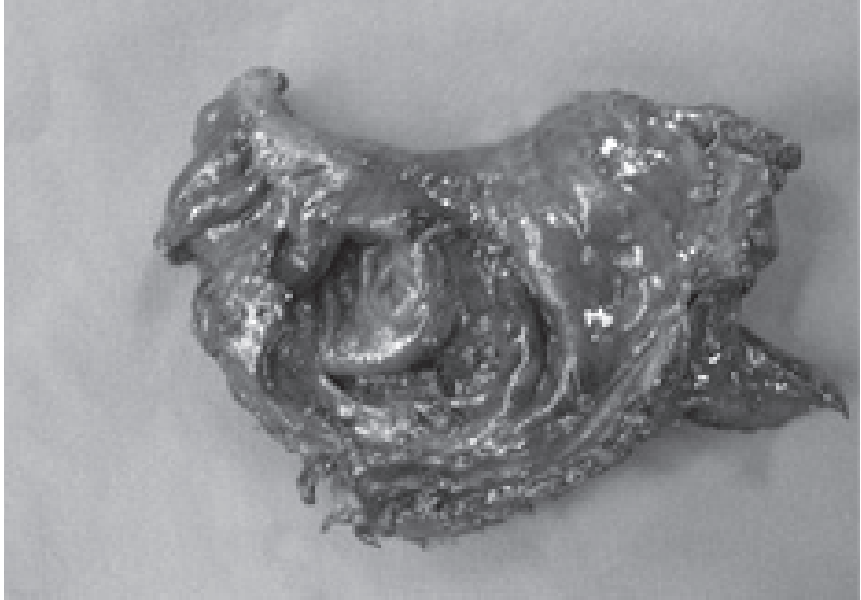

Fig. 3. Gross finding of the rectum showing a large perforation (about $3.5 \mathrm{~cm} \times 3 \mathrm{~cm})$.

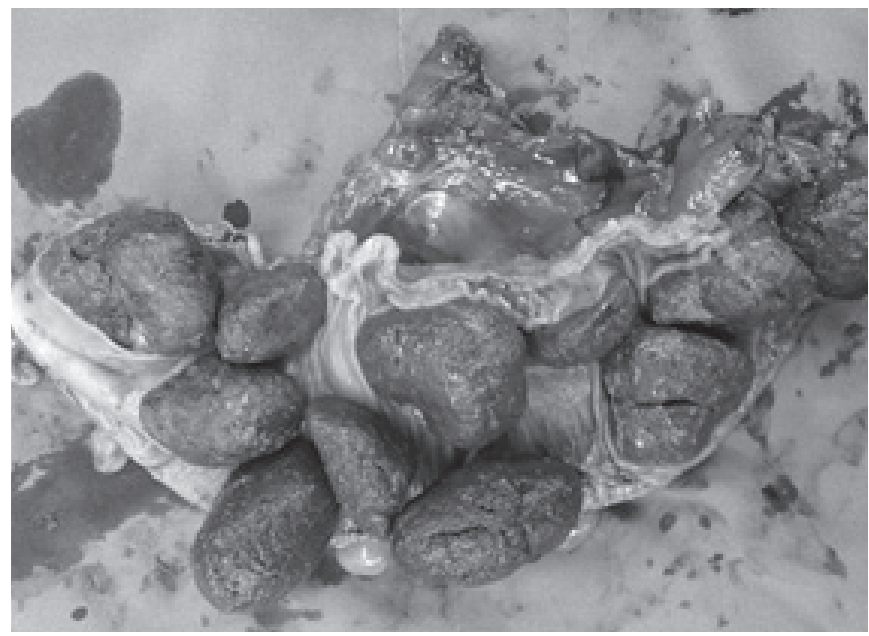

Fig. 4. Significant amount of firm stool in the sigmoid colon.

A hard fecaloma diminishes intestinal perfusion, causing local ischemia, mucosal necrosis, an ulcer and perforation [2].

Wood [6] reported that chest X-rays demonstrate free-air in only $30 \%$ of colon perforations. If a stercoral perforation is suspected, a CT scan should be considered. The most useful tool for the diagnosis of a stercoral perforation is an abdominopelvic CT scan [4]. A discontinuity in the enhancement of the bowel wall in relation to focal fecal distension of the colonic lumen could represent a stercoral perforation. In the present case, the chest X-ray did not reveal a pneumoperitoneum, but the CT scan demonstrated free-air in the upper rectum mesorectum and the retroperitoneum.

For a stercoral perforation, surgery seems to be the only therapeutic treatment, and Hartmann's surgery is known to be the treatment of choice [7]. Simple closure of the perforated site or segmental resection of the diseased colon with an anastomosis 
and a diverting enterostomy should be avoided [8]. Because of the inflammatory process in a long segment, ulcers and necrotic changes due to a fecaloma are usually multiple. Intraoperative colonoscopic exploration has been proposed to exclude additional stercoral ulcerations and delayed colonic perforations [7]. In our case, the patient was treated with a laparoscopic procedure. An emergent laparoscopic colon resection reduces the length of the postoperative hospital stay [9]. For patients older than 75 years, a laparoscopic resection of colon is associated with less intraoperative blood loss, a shorter hospital stay, fewer cardiac complications, and a lower mortality rate than an open resection [10]. However, for an accurate analysis of the outcomes of laparoscopy in emergent colon resections, more cases and data are required.

Constipation and fecal impaction are common patient presentations. Poorly-managed chronic constipation is the greatest risk for developing stercoral ulcers and perforations. When a patient with a history of chronic constipation visits the emergency room with diffuse abdominal pain, sepsis and/or rectal bleeding, we a stercoral colorectal perforation should be considered. An accurate diagnosis on a CT scan may facilitate early surgical intervention and improve the patient's prognosis.

This report showed that a stercoral rectal perforation can be successfully treated with a laparoscopic procedure. In elderly patients, chronic constipation must always be treated using dietetic and pharmacologic measures.

\section{CONFLICT OF INTEREST}

No potential conflict of interest relevant to this article was reported.

\section{REFERENCES}

1. Oakenful C, Lambrianides AL. Stercoral perforation of the rectum. Emerg Med Australas 2011;23:224-7.

2. Edden Y, Shih SS, Wexner SD. Solitary rectal ulcer syndrome and stercoral ulcers. Gastroenterol Clin North Am 2009;38:541-5.

3. Berry J. Dilatation and rupture of sigmoid flexure short report. $\mathrm{Br}$ Med J 1894;1:301.

4. Kumar P, Pearce O, Higginson A. Imaging manifestations of faecal impaction and stercoral perforation. Clin Radiol 2011;66:838.

5. Wang SY, Sutherland JC. Colonic perforation secondary to fecal impaction: report of a case. Dis Colon Rectum 1977;20:355-6.

6. Wood CD. Acute perforations of the colon. Dis Colon Rectum 1977;20:126-9.

7. Huang WS, Wang CS, Hsieh CC, Lin PY, Chin CC, Wang JY. Management of patients with stercoral perforation of the sigmoid colon: report of five cases. World J Gastroenterol 2006;12:500-3.

8. Kang J, Chung M. A stercoral perforation of the descending colon. J Korean Surg Soc 2012;82:125-7.

9. Ballian N, Weisensel N, Rajamanickam V, Foley EF, Heise CP, Harms BA, et al. Comparable postoperative morbidity and mortality after laparoscopic and open emergent restorative colectomy: outcomes from the ACS NSQIP. World J Surg 2012;36:2488-96.

10. She WH, Poon JT, Fan JK, Lo OS, Law WL. Outcome of laparoscopic colectomy for cancer in elderly patients. Surg Endosc 2013; 27:308-12. 